\title{
Prevalence and Influencing Factors of Mild Hypoglycaemia in People with Diabetes Type 1 and Type 2 in a Tertiary Care Centre: A Cross-Sectional Study
}

\author{
K Reise ${ }^{1,2}$, V Hartung 3 , UA Müller ${ }^{1,2}$, N Müller ${ }^{1,2}$, C Kloos ${ }^{1,2}$, T Lehmannn ${ }^{4}$, G Wolf ${ }^{1}$ and N Kuniss ${ }^{1,2 *}$ \\ ${ }^{1}$ Department of Internal Medicine III, Jena University Hospital, Germany \\ ${ }^{2}$ Diabetes Center Thuringia (Diabeteszentrum Thüringen e.V.), Germany \\ ${ }^{3}$ Department of Radiology, HELIOS Gotha, Germany \\ ${ }^{4}$ Institute of Medical Statistics, Computer Sciences and Documentation, Jena University Hospital, Germany
}

Submission: January 24, 2018; Published: March 19, 2018

*Corresponding author: Nadine Kuniss, Endocrinology and Metabolic Diseases, Department of Internal Medicine III, Jena University Hospital, Am Klinikum 1, D-07740 Jena, Germany, Email: nadine.kuniss@med.uni-jena.de

Abstract

Aims: The prevalence of severe hypoglycaemia is widely accepted to rate the quality of treatment in diabetes, however it is rarely. Mild hypoglycaemia is assessed on a regular basis in current drug studies but there is insufficient data for well-established drugs and regimens in routine care.

Methods: In 2009 we assessed the frequency and influencing factors of hypoglycaemia in 650 people with diabetes treated in a tertiary care centre: 162 type 1 diabetes [age $50+15$ years, diabetes duration $21+13$ years, BMI $\left.27 \pm 5 \mathrm{~kg} / \mathrm{m}^{2}, \mathrm{HbA}_{1 \mathrm{c}} 6.9+0.8 \%(52 \mathrm{mmol} / \mathrm{mol})\right]$; and 488 type 2 diabetes (age $67 \pm 10$ years, diabetes duration $16 \pm 9$ years, $\mathrm{BMI} 33 \pm 6 \mathrm{~kg} / \mathrm{m}^{2}, \mathrm{HbA}_{1 \mathrm{c}} 6.7 \pm 0.8 \%(50 \mathrm{mmol} / \mathrm{mol})$, insulin therapy $81 \%$ ).

Results: Frequency of mild hypoglycaemia/week is $1.61 \pm 1.75$ episodes in people with type 1 diabetes and $0.22 \pm 0.49$ in all participants with type 2 diabetes, $0.26 \pm 0.52$ in type 2 diabetes with insulin therapy, $0.16 \pm 0.44$ in type 2 diabetes with insulinotropic oral medication and $0.01 \pm 0.05$ with non-insulinotropic agents, respectively. Frequency of mild hypoglycaemia correlates negatively with age for participants with type 1 diabetes and positively with diabetes duration, severe hypoglycaemia/last 12 months and number of injections in type 2 diabetes on insulin therapy.

Conclusion: Frequency of mild hypoglycaemia is low in well-trained people in an outpatient diabetes cohort on tertiary care level. As the frequency of mild hypoglycaemia is predictive for severe hypoglycaemia in type 2 diabetes on insulin, it qualifies as a surrogate and thus an important marker to rate therapies and drugs.

Abbreviations: BMI: Body Mass Index; DCCT: Diabetes Control and Complications Trial; $\mathrm{HbA}_{1 c}$ : Glycated Haemoglobin $\mathrm{A}_{1 \mathrm{c}}$; MH: Mild Hypoglycaemia; SD: Standard Deviation; SH: Severe Hypoglycaemia; type 1 DM: Type 1 Diabetes Mellitus; type 2 DM: Type 2 Diabetes Mellitus

Keywords: Diabetes type 1; Diabetes type 2; Hypoglycaemia

\section{Introduction}

Severe hypoglycaemia ( $\mathrm{SH}$ ) is a potentially life-threatening condition, consequently its occurrence is an indicator for quality in diabetes care. In current therapeutic regimens $\mathrm{SH}$ is a rare event $[1,2]$. The Cochrane collaboration reviewed about long-acting insulin analogues compared to NPH insulin suggested mild hypoglycaemia (MH) as evaluation criterion for new drugs, as there was no significant difference for rates of SH shown in any of the included trials [3]. Reviews comparing sulphonylureas and glinides are exemplary for a lack of data in established therapeutic regimens, especially concerning $\mathrm{MH}$ $[4,5]$. Consequently the assessment of new drugs and diabetes therapies must consider markers occurring more frequently. In an effort to compare future studies with known therapeutic strategies, well-established regimens have to be reassessed. Another important disadvantage in using $\mathrm{MH}$ to assess quality of diabetes care is the inconsistency of definitions used throughout healthcare professionals, especially the threshold for hypoglycaemia differs between $2.8-3.9 \mathrm{mmol} / 1$ [6-10]. 
The aim of this study was to investigate the prevalence of MH and SH in people with type 1 diabetes mellitus (type $1 \mathrm{DM}$ ) and type 2 diabetes mellitus (type $2 \mathrm{DM}$ ) and to evaluate $\mathrm{MH}$ as a marker for quality of diabetes therapy. We propose a patientoriented definition of $\mathrm{MH}$ with occurring symptoms of $\mathrm{MH}$ as essential component and present data on the occurrence of $\mathrm{MH}$ in different diabetes types and therapies.

\section{Patients and Methods}

In 2009, all patients with type 1 or type 2 DM at a University outpatient Department for endocrinology and metabolic diseases in Germany were asked to answer a questionnaire about frequency and circumstances of hypoglycaemia in a crosssectional study. People were excluded if any of the following criteria were met: no medical diabetes treatment, new start of insulin therapy or other antidiabetic drug during the last 12 months as well as women with gestational diabetes.

MH was defined as a condition with symptoms consistent with hypoglycaemia and rapid attenuation after carbohydrate ingestion or a plasma glucose below $2.2 \mathrm{mmol} / \mathrm{l}$ without any symptoms [11,12]. According to the guidelines of the German Diabetes Association, SH was defined as the necessity for intravenous injection of glucose or glucagon intramuscular [13]. Three to six months prior to the study all participants were instructed to document every hypoglycaemia in their diary. We asked for $\mathrm{MH}$ in the last week or in the last 12 months if participants had less frequencies of hypoglycaemia. Episodes of SH were accessed for the last 12 months and in lifetime. Blood glucose self-measurements below $2.2 \mathrm{mmol} / \mathrm{l}$ without any symptoms were classified as impaired hypoglycaemia awareness.

Clinical and laboratory data such as gender, age, diabetes duration, antihyperglycaemic therapy, body mass index (BMI), glycosylated haemoglobin $\mathrm{A}_{1 \mathrm{c}}\left(\mathrm{HbA}_{1 \mathrm{c}}\right)$ and blood pressure were drawn from the digital patient record EMIL $₫$ [14] and collected on the day of the survey of the respective patient. $\mathrm{HbA}_{1 \mathrm{c}}$ was measured using high-performance liquid chromatography (TOSOH-Glykohämoglobin-Analyzer-HLC-723-GHbV;Tosoh, Tokyo, Japan). $\mathrm{HbA}_{1 \mathrm{c}}$ was adjusted according to the Diabetes Control and Complications Trial (DCCT): $\mathrm{HbA}_{1 \mathrm{c}}$ divided by the mean normal value $33 \mathrm{mmol} / \mathrm{mol}(5.2 \%)$ and multiplied by the mean normal $\mathrm{HbA}_{1 \mathrm{c}}$ of healthy people of the DCCT, i.e. $32 \mathrm{mmol} /$ mol (5.05\%) [15].

Social status was determined by education, highest professional position achieved and household net income [16]. A score ranging from 3 to 21 points was established. Higher score value indicates a higher social status. Participation in structured patient education programmes is part of the standard treatment of all patients with diabetes in Germany [17].

\section{Statistical Analysis}

Patient characteristics and their frequency of hypoglycaemia are given by adequate statistical measures (mean, standard deviation, frequency). The frequency of $\mathrm{MH}$ was calculated in subgroups and given as events per patient per week. The prevalence of SH was calculated as the proportion of patients with at least one SH during the last year. The event rate of $\mathrm{SH}$ during the last year was calculated in defined subgroups.

Confidence intervals (CI) at 95\% level were estimated to quantify the precision of prevalence estimates. Linear regression models were fitted for people with type 1 and type 2 DM to estimate the influence of age, diabetes duration, $\mathrm{SH}, \mathrm{HbA}_{1 c^{\prime}}$ number of injections per day and insulin dose per day on $\mathrm{MH}$. Associations were considered significant at $p \leq 0.05$. Statistical analysis was performed with SPSS for Windows 18.0 (SPSS Inc., Chicago, Il, USA) and R.2.11.0 [18].

\section{Results}

A total of 650 participants with type 1 DM $(n=162)$ and type 2 DM ( $n=488$ ) were interviewed. The characteristics of the enrolled cohort are shown in Table 1. Social status score was $12 \pm 4$ on average in type $1 \mathrm{DM}$ and $11 \pm 3$ in type $2 \mathrm{DM}$. In type 1 DM, 77\% ( $n=124)$ used an intensified insulin therapy, 3\% ( $n=4)$ a conventional insulin therapy and $21 \%(n=34)$ were treated with an insulin pump therapy. In type 2 DM, 81\% ( $n=393$ ) were treated with and $19 \%(\mathrm{n}=95)$ without insulin therapy. In people with insulin treated type $2 \mathrm{DM}, 45 \%(\mathrm{n}=176)$ had conventional, $35 \%(\mathrm{n}=137)$ multiple, $18 \%(\mathrm{n}=69)$ preprandial insulin therapy as well as $3 \%(\mathrm{n}=11)$ basal insulin only. In addition to insulin therapy, $38 \%$ were treated with oral agents, such as metformin.

Table 1: Patient characteristics of the participants.

\begin{tabular}{|c|c|c|c|c|c|c|c|c|}
\hline & \multicolumn{5}{|c|}{ Type 1 DM } & \multicolumn{3}{|c|}{ Type 2 DM } \\
\hline & all $(n=162)$ & ICT $(n=124)$ & $\operatorname{CSII}(n=34)$ & CT $(n=4)$ & all $(n=488)$ & $\begin{array}{c}\text { Insulin } \\
(n=393)\end{array}$ & $\begin{array}{l}\text { Insulino-tropic } \\
\text { OHA }(n=45)\end{array}$ & $\begin{array}{c}\text { Non-insulino-tropic } \\
\text { OHA }(n=50)\end{array}$ \\
\hline Women\% (n) & $42(68)$ & $39(48)$ & $53(18)$ & $50(2)$ & $42(206)$ & $41(161)$ & $44(20)$ & $50(25)$ \\
\hline Age (y) & $50 \pm 15$ & $50 \pm 15$ & $49 \pm 15$ & $61 \pm 14$ & $67 \pm 10$ & $67 \pm 10$ & $68 \pm 10$ & $62 \pm 11$ \\
\hline $\begin{array}{c}\text { Diabetes } \\
\text { duration (y) }\end{array}$ & $21 \pm 13$ & $20 \pm 14$ & $25 \pm 12$ & $8 \pm 7$ & $16 \pm 9$ & $17 \pm 9$ & $12 \pm 9$ & $7 \pm 5$ \\
\hline $\begin{array}{l}\text { Insulin dose } \\
\text { (IU/kg/day) }\end{array}$ & $0.6 \pm 0.3$ & $0.7 \pm 0.3$ & $0.5 \pm 0.2$ & $0.4 \pm 0.1$ & $0.5 \pm 0.5$ & $0.7 \pm 0.4$ & $\sim$ & $\sim$ \\
\hline BGSM (n/w) & $34 \pm 8$ & $34 \pm 8$ & $38 \pm 7$ & $20 \pm 11$ & $19 \pm 11$ & $22 \pm 9$ & $5 \pm 7$ & $3 \pm 5$ \\
\hline HbA1c (\%)* & $7.5 \pm 0.8$ & $7.5 \pm 0.8$ & $7.5 \pm 0.9$ & $6.6 \pm 0.8$ & $7.3 \pm 0.9$ & $7.3 \pm 0.9$ & $7.2 \pm 0.9$ & $6.8 \pm 0.7$ \\
\hline
\end{tabular}




\section{Current Research in Diabetes \& Obesity Journal}

\begin{tabular}{|c|c|c|c|c|c|c|c|c|}
\hline $\begin{array}{c}\mathrm{HbA1c} \\
\text { (mmol/mol)* }\end{array}$ & 58 & 58 & 58 & 49 & 56 & 56 & 55 & 51 \\
\hline BMI $\left(\mathrm{kg} / \mathrm{m}^{2}\right)$ & $27 \pm 5$ & $26 \pm 5$ & $27 \pm 4$ & $32 \pm 8$ & $33 \pm 6$ & $33 \pm 6$ & $29 \pm 5$ & $34 \pm 7$ \\
\hline $\begin{array}{l}\text { Blood } \\
\text { pressure } \\
\text { systolic } \\
\text { (mmHg) }\end{array}$ & $141 \pm 18$ & $141 \pm 19$ & $138 \pm 17$ & $138 \pm 17$ & $146 \pm 19$ & $146 \pm 19$ & $143 \pm 20$ & $143 \pm 19$ \\
\hline $\begin{array}{c}\text { Blood } \\
\text { pressure } \\
\text { diastolic } \\
(\mathrm{mmHg})\end{array}$ & $85 \pm 11$ & $84 \pm 11$ & $86 \pm 11$ & $87 \pm 14$ & $83 \pm 12$ & $82 \pm 12$ & $83 \pm 13$ & $88 \pm 11$ \\
\hline
\end{tabular}

BGSM: Blood Glucose Self Monitoring; BMI: Body Mass Index; CSII: Continuous Subcutaneous Insulin Infusion (=insulin pump therapy); CT: Conventional Therapy; DM: Diabetes Mellitus; ICT: Intensified Conventional Therapy; IU: Insulin Units; OHA: Oral Hypoglycaemic Agent.

*HbA1c DCCT adjusted

Blood glucose self-monitoring performed $100 \%$ of the participants with type 1 as well as with type 2 DM and insulin therapy. $64 \%$ of people with type $2 \mathrm{DM}$ and insulinotropic drugs ( $5 \pm 7$ per week,) as well as $56 \%$ of individuals with noninsulinotropic drugs $(3 \pm 5$ per week, max. 28) measured their blood glucose.

Prevalence of MH is shown in Table 2. In type 1 DM 97.5\% (CI: $95.1 \%, 100 \%)$ had at least one hypoglycaemia per year, 53.9\% (CI: 49.5\%, 58.3\%) in all participants with type $2 \mathrm{DM}, 61.6 \%$ (CI: $56.8 \%, 66.4 \%$ ) in type $2 \mathrm{DM}$ with insulin therapy and $22.1 \%$ (CI: $13.6 \%, 30.6 \%$ ) in people with type $2 \mathrm{DM}$ without insulin therapy Table 2: Prevalence and frequency of mild and severe hypoglycaemia.
(40.0\% insulinotropic oral hypoglycaemic agents and 6.0\% noninsulinotropic agents).

The event rate of MH was 1.61 episodes per patient per week in type 1 DM, 0.22 in all type 2 DM, 0.26 in type 2 DM with insulin therapy, 0.16 in type 2 with insulinotropic oral medication and 0.01 in type $2 \mathrm{DM}$ with non-insulinotropic agents, respectively. 14 participants with type $1 \mathrm{DM}(8.6 \%$, CI: $4.3 \%, 13.0 \%)$ reported 19 episodes of SH during the last 12 months. Seven participants with type 2 DM and insulin therapy (1.4\%, CI: 0.4\%, 2.5\%) had eleven episodes of $\mathrm{SH}$, no participant without insulin therapy reported a SH. The event rate of SH is shown in Table 2.

\begin{tabular}{|c|c|c|c|c|c|c|c|c|}
\hline & \multicolumn{3}{|c|}{ Type 1 DM } & \multicolumn{3}{c|}{ Type 2 DM } \\
\cline { 2 - 9 } & all (n=162) & ICT (n=124) & CSII (n=34) & CT (n=4) & all (n=488) & $\begin{array}{c}\text { Insulin } \\
\text { (n=393) }\end{array}$ & $\begin{array}{c}\text { Insulino- } \\
\text { tropic OHA } \\
\text { (n=45) }\end{array}$ & $\begin{array}{c}\text { Non-insulino- } \\
\text { tropic OHA } \\
\text { (n=50) }\end{array}$ \\
\hline $\begin{array}{c}\text { People with } \\
\text { MH\% (n) }\end{array}$ & $97.5(158)$ & $97.5(120)$ & $100(34)$ & $100(4)$ & $54(263)$ & $62(242)$ & $40(18)$ & $6(3)$ \\
\hline $\begin{array}{c}\text { Frequency of } \\
\text { MH per week }\end{array}$ & $1.61 \pm 1.75$ & $1.58 \pm 1.85$ & $1.84 \pm 1.37$ & $0.67 \pm 1.22$ & $0.22 \pm 0.49$ & $0.26 \pm 0.52$ & $0.16 \pm 0.44$ & $0.01 \pm 0.05$ \\
\hline $\begin{array}{c}\text { Frequency of } \\
\text { SH per year }\end{array}$ & $0.12 \pm 0.03$ & $0.11 \pm 0.04$ & $0.15 \pm 0.06$ & $\sim$ & $0.02 \pm 0.02$ & $0.03 \pm 0.01$ & $\sim$ & $\sim$ \\
\hline
\end{tabular}

CSII: Continous Subcutaneous Insulin Infusion (= insulin pump therapy); CT: Conventional Therapy; DM: Diabetes Mellitus; ICT: Intensified Conventional Therapy; MH: Mild Hypoglycaemia; OHA: Oral Hypoglycaemic Agent; SH: Severe Hypoglycaemia.

In type $1 \mathrm{DM}$, frequency of $\mathrm{MH}$ decreased with age $(ß=-0.24$ per year, $\mathrm{p}=0.007)$. Duration of diabetes, $\mathrm{SH}$ during the last 12 months, $\mathrm{HbA}_{1 \mathrm{c}}$, number of injections and insulin dose were not associated with MH. In type $2 \mathrm{DM}$ with insulin therapy, one year longer diabetes duration increased the frequency of MH by 0.20

per year $(\mathrm{p}<0.001)$. There was also a significant increase of $\mathrm{MH}$ by SH $(0.17$ per each $\mathrm{SH} /$ year, $\mathrm{p}<0.001)$ and number of insulin injections ( 0.13 per each injection, $p=0.023$ ). In type $2 \mathrm{DM}$ with oral hypoglycaemic agents, frequency of $\mathrm{MH}$ was not associated with age, diabetes duration and $\mathrm{HbA}_{1 \mathrm{c}}$ (Table 3).

Table 3: Association of frequency of mild hypoglycaemia with covariables.

\begin{tabular}{|c|c|c|c|c|c|c|}
\hline \multirow[t]{2}{*}{ Independent Variable } & \multicolumn{2}{|c|}{ Type 1 DM } & \multicolumn{2}{|c|}{ Type 2 DM with Insulin } & \multicolumn{2}{|c|}{ Type 2 DM OHA } \\
\hline & $\boldsymbol{B}^{\mathrm{MH}}$ & p Value & $\mathbf{B}^{\mathrm{MH}}$ & p Value & $\mathbf{B}^{\mathrm{MH}}$ & p Value \\
\hline Age (years) & -0.236 & 0.007 & -0.069 & 0.22 & 0.021 & 0.857 \\
\hline Diabetes duration (years) & 0.079 & 0.365 & 0.204 & $<0.001$ & -0.008 & 0.948 \\
\hline Frequency of SH per year & 0.045 & 0.572 & 0.173 & $<0.001$ & $\sim$ & $\sim$ \\
\hline $\mathrm{HbA}_{1 \mathrm{c}}(\%)$ & 0.012 & 0.886 & 0.073 & 0.16 & 0.053 & 0.633 \\
\hline Number of insulin injections (n/day) & 0.1 & 0.218 & 0.13 & 0.023 & $\sim$ & $\sim$ \\
\hline Insulin dose (IU/kg/day) & -0.123 & 0.133 & -0.016 & 0.78 & $\sim$ & $\sim$ \\
\hline
\end{tabular}




\section{Current Research in Diabetes \& Obesity Journal}

$11 \%$ of participants with type $1 \mathrm{DM}$ as well as $1 \%$ of people with insulin treated type $2 \mathrm{DM}$ measured blood glucose levels below $2.2 \mathrm{mmol} / \mathrm{l}$ without any symptoms. These participants showed a lower threshold for first symptoms of hypoglycaemia (type $1 \mathrm{DM}$ : $2.6 \pm 1.0$ vs. $3.4 \pm 0.6 \mathrm{mmol} / \mathrm{l}, \mathrm{p}<0.001$; type $2 \mathrm{DM}$ : $3.0 \pm 1.0$ vs. $3.7 \pm 0.7 \mathrm{mmol} / \mathrm{l}, \mathrm{p}=0.032$ ) and monitored their blood glucose more often (type $1 \mathrm{DM}$ : $39 \pm 8 \mathrm{vs}$. $34 \pm 8$ per week, $\mathrm{p}=0.013$; type 2 DM: $32 \pm 4$ vs. $22 \pm 9$ per week, $p=0.024$ ) than those with normal awareness of hypoglycaemia symptoms. The frequency of $\mathrm{MH}$ and $\mathrm{SH}$ is not associated with impaired hypoglycaemia awareness.

\section{Discussion}

Recently, the occurrence and frequency of $\mathrm{MH}$, especially in people with type $2 \mathrm{DM}$, roused more attention due to upcoming GLP1 agonists and DDP4 inhibitors with a reduced risk of hypoglycaemia [19,20]. This potential advantage may lose its relevance in the light of the reported results of well-educated patients with type $2 \mathrm{DM}$ under oral hypoglycaemic therapy with a low prevalence of $\mathrm{MH}$ with 0.08 events per week. In addition, the influence of MH on patients' quality of life seems surprisingly low as Pramming et al. [21] have shown that worries about $\mathrm{MH}$ are not correlated with their frequency in people with type $1 \mathrm{DM}$. Another investigation of Kuniss et al. [22] showed that MH is not associated with increased diabetes-related distress or burden in people with type 1 or type 2 DM.

As the definition of hypoglycaemia significantly influences its prevalence, a consistent definition throughout studies, centres and healthcare professionals is a necessity for comparable data. A threshold between $2.7 \mathrm{mmol} / \mathrm{l}$ (German Diabetes Association) and $\leq 3.9 \mathrm{mmol} / \mathrm{l}$ (American Diabetes Association) is often used to define hypoglycaemia [6-10]. In our study only the half of people with type $2 \mathrm{DM}$ and oral agents measure their blood glucose regularly, so this definition is inappropriate. Therefore, we defined hypoglycaemia on the basis of typical symptoms like sweating, loss of concentration or feeling shaky. Different criteria are necessary for different types of diabetes or different therapy regimes [23].

The rates of $\mathrm{MH}$ among our patients with type $1 \mathrm{DM}$ correspond to the findings of one other study from Germany (1.6 per patient per week, both) [24] and are only slightly lower than the rates reported in an earlier European multi-centre study which used similar methods (1.8 per patient per week) [25]. Another prospective single-centre study in a Scottish cohort reported half as much incidents of $\mathrm{MH}(0.8$ per patient per week) with a higher $\mathrm{HbA}_{1 \mathrm{c}}$ of $8.5 \%$ in patients with type $1 \mathrm{DM}$ [26]. In people with insulin treated type 2 DM our results correspond to the data from the Scottish study ( 0.3 per patient per week, both) and are only slightly lower than the reported rates of $\mathrm{MH}$ in the German and European studies (0.4-0.8 episodes/patient/ week).

Compared to UK Hypoglycaemia Study Group data published in 2007, our participants had a similar prevalence with a higher event rate of MH (type 1 DM: 85-87\% vs. 98\%, 29.0-35.5 vs. 83.7 events per patient-year; insulin-treated type 2 DM: 51-64\% vs. $62 \%, 4.1-10.2$ vs. 13.5 events per patient-year; type 2 DM with insulinotropic OHA: 39 vs. $40 \%, 1.9$ vs. 8.3 events per patientyear) [27].

Considering the characteristics of the participants there is much difference to other studies which impairs comparability. Our participants had longer diabetes duration, were older, had lower $\mathrm{HbA}_{1 \mathrm{c}}$ and were assigned to structured education programmes. The criterion of third party assistance is the most probable reason for a tenfold lower prevalence of SH in our cohort in comparison to studies also based on recalled hypoglycaemia (type 1 DM: 0.1 vs. 0.7-1.0; type 2 DM with insulin: 0.03 vs. 0.1$0.5)[24,25]$. Still, the ratio in the frequency of SH in type $2 \mathrm{DM}$ versus type $1 \mathrm{DM}$ of one to three is identical to the numbers reported in other studies [24-26].

We used a simple, straightforward item to assess hypoglycaemia unawareness, because there is no gold standard and even in the three standardised questionnaires there is a wide spectrum of prevalence (26-63\%) [28]. The frequency of $\mathrm{MH}$ was not associated with impaired hypoglycaemia awareness in our patients. The value of $\mathrm{HbA}_{1 \mathrm{c}}$ to ensure appropriate treatment and prevent long term complications is largely agreed on $<7.5 \%$ in patients with type $1 \mathrm{DM}$ and $6.5 \%-7.5 \%$ in type $2 \mathrm{DM}$ without SH $[10,14,15,29,30]$. There is ongoing debate whether focusing on $\mathrm{HbA}_{1 \mathrm{c}}$ alone may be sufficient to describe treatment quality. The position statement of the DDG working group for measurement of $\mathrm{HbA}_{1 \mathrm{c}}$ as well as Müller Wieland et al. [31] make mention of the considerable variability of $\mathrm{HbA}_{1 \mathrm{c}}$ measurements depending on the method in spite of the standardisation of the International Federation of Clinical Chemistry and Laboratory Medicine [31,32]. In our study $\mathrm{HbA}_{1 \mathrm{c}}$ was measured using highperformance liquid chromatography (official normal range 25$41 \mathrm{mmol} / \mathrm{mol}$ (4.4-5.9\%); mean $33 \mathrm{mmol} / \mathrm{mol}$ (5.2\%); TOSOHGlykohämoglobin-Analyzer-HLC-723-GHbV; Tosoh, Tokyo, Japan). The normal range was found to have shifted in 2010 after retesting the normal range in 150 healthy volunteers without diabetes. This was confirmed by a mean $\mathrm{HbA}_{1 \mathrm{c}}$ of $38 \mathrm{mmol} /$ mol (5.65 $\pm 0.38 \%)$ in 1079 people without diabetes in 2009 [33]. This could have caused overtreatment in some patients in consequence of more $\mathrm{MH}$. Additionally our study shows that the frequency of $\mathrm{MH}$ rises in people with insulin-treated type $2 \mathrm{DM}$ with time since diagnosis and number of injections, regardless of $\mathrm{HbA}_{1 \mathrm{c}}$ levels or insulin dose, which might also be a hint for overtreatment.

Normal $\mathrm{HbA}_{1 \mathrm{c}}$ levels rise with age also in people without diabetes [34,35], whereas it gives no specific target values for elderly and also long time complications lose their relevance. So it seems to be more appropriate to reduce impairment in quality of life by avoiding hypoglycaemic events. Here, the frequency of $\mathrm{MH}$ as clinical and patient-oriented target value is the superior marker. The present study was conducted in a tertiary care centre in a University outpatient Department in a cross-sectional 
setting. There are specific limitations to that design, such as recall bias. However, one study recording the frequency of MH in the same cohort prospectively as well as retrospectively indicates that recall bias in retrospective data collection of hypoglycaemia in the last week is not significant [24].

\section{Conclusion}

For the first time, estimates are provided for the frequency of $\mathrm{MH}$ in several common diabetic therapeutic regimens in people with type $1 \mathrm{DM}$ and type $2 \mathrm{DM}$ who have participated in a structured treatment and teaching programme.

Considering all the aspects above, we suggest to incorporate the systematic assessment of $\mathrm{MH}$ into clinical routine. Furthermore, consideration of the frequency of $\mathrm{MH}$ as an additional marker of diabetic treatment quality should find its way in diabetes treatment guidelines and disease management programmes. Frequency of MH may improve monitoring and evaluation of diabetes therapies when $\mathrm{HbA}_{1 \mathrm{c}}$ alone might not provide an adequate target value.

\section{Acknowledgement}

The authors thank all patients for participation and all nurses in our outpatient Department, especially Sylvia Drewelow, for their contribution to this study.

\section{Statement of Human and Animal Rights}

All procedures followed were in accordance with the ethical standards of the responsible committee on human experimentation (institutional and national) and with the Helsinki Declaration of 1975, as revised in 2008 [5].

\section{Statement of Informed Consent}

Informed consent was obtained from all patients for being included in the study.

\section{References}

1. Müller N, Schiel R, Osterbrink B, Holl RW, Kerner W, et al. (2008) Care and Outcome in Patients with Diabetes Mellitus Type 1 and Type 2 in Specialized Practice, Diabetes Specialized Hospital and Diabetes Department of a Regional General Hospital in Germany 2005. Diabetologia 3: 41-50.

2. Sämann A, Lehmann T, Heller T, Müller N, Hartmann P, et al. (2012) A retrospective study on the incidence and risk factors of severe hypoglycemia in primary care. Fam Pract 30(3): 290-293.

3. Horvath K, Jeitler K, Berghold A, Ebrahim SH, Gratzer TW, et al. (2007) Long-acting insulin analogues versus NPH insulin (human isophane insulin) for type 2 diabetes mellitus. Cochrane Database Syst Rev (2): CD005613.

4. (2009) Glinides in the treatment of diabetes mellitus type 2. Institute for Quality and Efficiency in Health Care, Germany, pp: 1-7.

5. Hemmingsen B, Schroll JB, Lund SS, Wetterslev J, Gluud C, et al. (2013) Sulphonylurea monotherapy for patients with type 2 diabetes mellitus. Cochrane Database Syst Rev (4): CD009008.

6. Badenhoop K, Bojunga J, Usadel HU (2003) Hypoglykämie. In: Mehnert H, Standl E, Usadel KH, Häring HU (Eds.), Diabetologie in Klinik und Praxis. Thieme, Germany.
7. Brückel J (2003) Hypoglykämie. In: Hrsg Böhm BO, Palitzsch KD, Rosak C, Spinas GA (Eds.), Klinische Diabetologie..

8. American Diabetes Association (2017) Standards of medical care in diabetes 2017. Diabetes Care 40 (suppl 1): 1-142.

9. European Agency for Evaluation of Medicinal Products (2012) Guideline on clinical investigation of medicinal products in the treatment or prevention of diabetes mellitus.

10. Clayton D, Woo V, Yale JF (2013) Canadian Diabetes Association 2013 Clinical Practice Guidelines for the Prevention and Management of Diabetes in Canada: Hypoglycemia. Can J Diabetes 37 (suppl 1): 69-71.

11. Whipple AO (1938) The surgical therapy of hyperinsulinism. J Internat Chir 3: 237-276.

12. Marks V (1976) The measurement of blood glucose and the definition of hypoglycemia. Horm Metab Res Suppl 6: 1-6.

13. Bundesärztekammer (BÄK), Kassenärztliche Bundesvereinigung (KBV), Arbeitsgemeinschaft der Wissenschaftlichen Medizinischen Fachgesellschaften (AWMF). Nationale VersorgungsLeitlinie Therapie des Typ-2-Diabetes - Langfassung, 1. Auflage, Version 4, August 2013, zuletzt geändert November 2014.

14. Schumann M (2013) Electronic Medical Information System for longterm documentation of chronic diseases (EMIL).

15. The Diabetes Control and Complications Trial Research Group (1993) The effect of intensive treatment of diabetes on the development and progression of long-term complications in insulin-dependent diabetes mellitus. J Pediatr 125(2): 177-188.

16. Dulon M, Bardehle D, Blettner M (2003) Assessing social inequality in microcensus data and German national health examination survey. Gesundheitswesen 65(11): 629-635.

17. www.patientenschulungsprogramme.de

18. R Development Core Team (2010) R: A language and environment for statistical computing. R Foundation for Statistical Computing, Vienna, Austria.

19. Gallwitz B, Rosenstock J, Rauch T, Bhattacharya S, Patel S, et al. (2012) 2 -year efficacy and safety of linagliptin compared with glimepiride in patients with type 2 diabetes inadequately controlled on metformin: a randomised, double-blind, non-inferiority trial. Lancet 380(9840): 475-483.

20. Nauck M, Frid A, Hermansen K, Thomsen AB, During M, et al. (2012) Long-term efficacy and safety comparison of liraglutide, glimepiride and placebo, all in combination with metformin in type 2 diabetes: 2-year results from the LEAD-2 study. Diabetes Obes Metab 15(3): 204-212.

21. Pramming S, Thorsteinsson B, Bendtson I, Binder C (1991) Symptomatic hypoglycaemia in 411 type 1 diabetic patients. Diabet Med 8(3): 217-222.

22. Kuniss N, Kramer G, Müller N, Kloos C, Wolf G, et al. (2016) History of mild hypoglycaemia does not affect the prevalence of diabetes-related distress in people with diabetes. Acta Diabetologica 53(5): 833-838.

23. Seaquist ER, Anderson J, Childs B, Cryer P, Dagogo Jack S, et al. (2013) Hypoglycemia and diabetes: a report of a workgroup of the American Diabetes Association and the Endocrine Society. J Clin Endocrinol Metab 36(5): 1384-1395.

24. Kulzer B, Seitz L, Kern W (2014) Real-world patient-reported rates of non-severe hypoglycaemic events in Germany. Exp Clin Endocrinol Diabetes 122(3): 167-172.

25. Ostenson CG, Geelhoed Duijvestijn P, Lahtela J, Weitgasser R, Markert Jensen M, et al. (2013) Self-reported non-severe hypoglycaemic events in Europe. Diabet Med 31(1): 92-101. 


\section{Current Research in Diabetes \& Obesity Journal}

26. Donnelly LA, Morris AD, Frier BM, Ellis JD, Donnan PT, et al. (2005) Frequency and predictors of hypoglycaemia in Type 1 and insulintreated Type 2 diabetes: a population-based study. Diabet Med 22(6) 749-755.

27. UK Hypoglycaemia Study Group (2007) Risk of hypoglycaemia in types 1 and 2 diabetes: effects of treatment modalities and their duration. Diabetologia 50(6): 1140-1147.

28. Gold AE, MacLeod KM, Frier BM (1994) Frequency of severe hypoglycemia in patients with type I diabetes with impaired awareness of hypoglycemia. Diabetes Care 17(7): 697-703.

29. Wang PH, Lau J, Chalmers TC (1993) Meta analysis of the effects of intensive glycemic control on late complications of type I diabetes mellitus. Lancet 341(8856): 1306-1309.

30. The Diabetes Control and Complications Trial Research Group (1995) Adverse events and their association with treatment regimens in the diabetes control and complications trial. Diabetes Care 18(11): 14151427.
31. Müller Wieland D, Petermann A, Nauck M, Heinemann L, Kerner W, et al. (2016) Definition, Klassifikation und Diagnostik des Diabetes mellitus. Diabetologie 11(suppl 2): S78-S81.

32. Kerner W, Freckmann G, Müller UA, Roth J, Schleicher E, et al. (2015) Position statement of the DDG working group for measurement of $\mathrm{HbA}_{1 \mathrm{c}^{*}}$ Diabetologie und Stoffwechsel 10(06): 329-333.

33. Kloos C, Heller T, Böer K, Hunger Battefeld W, Wolf G, et al. (2011) Unnoticed shift in the normal range of glycated $\mathrm{HbA}_{1 \mathrm{c}}$ with TOSOH high performance liquid chromatography. EASD Lisbon P985.

34. Pani LN, Korenda L, Meigs JB, Driver C, Chamany S, et al. (2008) Effect of aging on $A_{1 C}$ levels in individuals without diabetes: evidence from the Framingham Offspring Study and the National Health and Nutrition Examination Survey 2001-2004. Diabetes Care 31(10): 1991-1996.

35. Roth J, Müller N, Lehmann T, Heinemann L, Wolf G, et al. (2016) HbA and age in non-diabetic subjects: an ignored association? Exp Clin Endocrinol Diabetes.

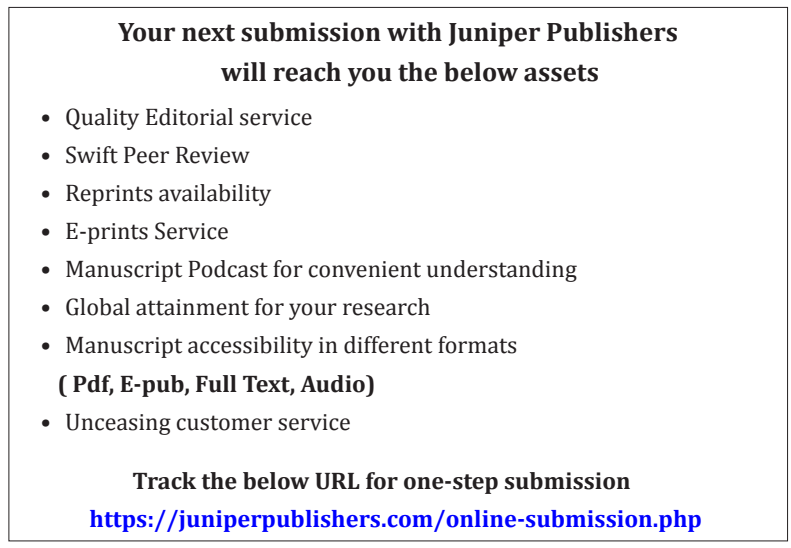

